\title{
.
}

\author{
Ramón Casilda Béjar*
}

\section{LAS EMPRESAS MULTILATINAS}

Las empresas multilatinas representan un fenómeno empresarial realmente novedoso en América Latina, que se explica debido al crecimiento y desarrollo económico que ha protagonizado la región desde mediados de la década de 1990, impulsado por un entorno internacional muy favorable. Desde entonces, compiten abiertamente con las multinacionales extranjeras en los más diversos sectores de actividad, lo que les ha permitido poner a prueba sus habilidades directivas, sus capacidades productivas y sus fortalezas económicas.

Palabras clave: internacionalización, fusiones, adquisiciones, competitividad, modernización, multinacionales.

Clasificación JEL: F01, G34, O14.

\section{Introducción}

Originalmente, las empresas multilatinas fueron definidas por la revista América Economía en 1996. Su objetivo era describir las empresas locales que comenzaban a realizar negocios a lo largo y ancho de las Américas. Recuérdese que por estos años comenzaba la presencia de las empresas españolas en la región.

Con las multilatinas, igual que sucede con las empresas multinacionales, se puede decir que los nombres colectivos constituyen una abstracción útil cuando definen una idea $o$ una cosa con cierto grado de precisión. Como

\footnotetext{
* Profesor del Instituto Universitario de Investigación en Estudios Latinoamericanos (IELAT) de la Universidad de Alcalá y de la Escuela Diplomática del Ministerio de Asuntos Exteriores, Unión Europea y Cooperación.

Versión de agosto de 2018.
}

sucede con la definición del concepto de «empresa multinacional», que ha sido y es objeto de discusión y debate en la literatura especializada, en gran medida debido a la amplia heterogeneidad que presentan estas organizaciones y a su propia evolución en el tiempo, muy probablemente, esto mismo les sucederá a las empresas multilatinas en la medida que continúen avanzando, se intensifique su internacionalización, su tamaño y su nivel de complejidad.

Las multilatinas forman parte de un grupo de empresas que se diferencian de aquellas multinacionales originadas en Estados Unidos, Europa o Asia. Puede decirse que constituyen una nueva generación de «multinacionales regionales», aún de corta experiencia en el manejo de la inversión extranjera directa y negocios internacionales, ya que se caracterizan por operar dentro de la propia región. 
Según la revista América Economía (2014), para que una empresa sea «multilatina» debe cumplir los siguientes criterios:

- Ser de origen latinoamericano.

- Tener una facturación igual o superior a 250 millones de dólares anuales.

- Contar con operaciones, además de en su país, en al menos otro país de la región.

Estos criterios que las definen podrían completarse con otros como el «nivel de propiedad o inversión", que es lo que le permite el control de la empresa, algo que sí se encuentra presente en la definición de la empresa multinacional. También, como sucedió con las multinacionales, los criterios que las definen variarán con en el tiempo, conforme se vayan desarrollando, ya que las multinacionales no cuentan ni con una teoría completa ni con una definición de general aceptación.

De manera que las empresas multilatinas representan un fenómeno típicamente latinoamericano, adaptado y de acuerdo con sus circunstancias y entorno económico, productivo, institucional y social.

\section{Las multilatinas y su expansión regional en el siglo xxI}

Iniciado el siglo xxı, la expansión regional de las multilatinas coincidió con un buen momento económico, propiciado por los altos precios de las materias primas, que se incrementaron notablemente debido a la intensa demanda china y a un entorno internacional muy favorable, lo cual resultó ser una condición decisiva para que se iniciara un ciclo de crecimiento económico vigoroso en la región, que le proporcionó excelentes resultados, que a su vez propiciaron la confianza de los inversores.

Así, las estrategias de expansión regional, que buscaban obtener mayor tamaño, diversificación y beneficios, se vieron favorecidas por la instauración de múltiples acuerdos comerciales, cuyo fin es favorecer la integración regional mediante intercambios entre las distintas economías que participan de estos tratados regionales, los cuales se han comportado con distinta intensidad, como, por ejemplo, Mercosur y la Alianza del Pacífico.

Sobre las estrategias de crecimiento regional que han utilizado, son diferentes y no son ajenas a las propias singularidades de sus países de procedencia, si bien comparten algunos patrones comunes. Por ejemplo, las chilenas prefieren crecer en el bloque que conforman Perú, Argentina, Colombia y Brasil. La fórmula más utilizada ha sido, y sigue siendo, las fusiones y las adquisiciones (M\&A).

Como ejemplo se encuentra la protagonizada por el mayor banco privado brasileño, Itaú Unibanco, que fusionó su filial en Chile con el colombiano CorpBanca, una operación que le proporciona el acceso a los mercados de Colombia, Perú y América Central. La entidad resultante, Itaú CorpBanca, tiene como socios mayoritarios Itaú Unibanco y CorpGroup.

Además, se encuentra la fusión que protagonizaron la aerolínea chilena Lan Chile y la brasileña TAM, dando origen a LATAM, que se sitúa entre las diez aerolíneas más importantes del mundo, proporcionando servicios de transporte de pasajeros y de carga a más de cien destinos y veinte países.

Las empresas aéreas, tomadas como referencia de expansión regional debido a su naturaleza, constituyen un sector en constante transformación en busca de mayor tamaño, $\triangleright$ 
para competir internacionalmente, lo cual le exige ser muy intensivo en capital y contar con economías de red que faciliten la integración de filiales en diferentes países para construir marcas globales.

Al mismo tiempo, por su carácter estratégico, es un sector muy regulado y protegido por los Gobiernos nacionales. De hecho, en América Latina es uno de los pocos sectores donde la propiedad extranjera de las empresas está limitada por ley. Estos factores han generado una consolidación parcial de la industria, dominada completamente por empresas de la región (CEPAL, 2014).

Durante la apertura y liberalización de los servicios públicos, que tuvo lugar en los años 1990, se podría haber sospechado que las aerolíneas seguirían el mismo camino que las empresas eléctricas o de telecomunicaciones y acabarían controladas por grupos extranjeros; sin embargo, la realidad ha sido muy diferente.

De hecho, las adquisiciones por inversionistas internacionales fueron pocas y sin éxito. La principal fue la de Aerolíneas Argentinas, comprada sucesivamente por Iberia y Marsans - ambas españolas - antes de ser renacionalizada en 2008. Del mismo modo, Continental adquirió una participación mayoritaria en Copa de Panamá, empresa que tampoco generó los beneficios esperados, lo que indujo a Continental a retirarse a partir de 2005 hasta salirse completamente.

En contradicción con los resultados de las operaciones emprendidas por compañías extranjeras, la integración de empresas locales y regionales en la industria aérea ha avanzado considerablemente durante los últimos años. El ejemplo principal es LATAM, actualmente la línea aérea más grande de América Latina y el Caribe, con posiciones relevantes mediante LAN Perú, líder en este país, uniéndose LAN
Colombia y LAN Argentina, segundas aerolíneas más importantes en sus respectivos mercados.

Como segundo grupo aéreo más importante de la región se encuentra Avianca, anteriormente la compañia aérea nacional de Colombia, que se fusionó en 2009 con TACA Airlines ${ }^{1}$, de origen centroamericano, con sede en El Salvador, y que previamente había absorbido a Lacsa, la aerolínea de Costa Rica. Desde 2013 Avianca ha unificado bajo su marca sus filiales en Brasil, Costa Rica, Ecuador, El Salvador, Guatemala, Honduras, Nicaragua y Perú. Con sus extensas operaciones, Avianca ofrece una red más densa de servicios que sus principales competidores. Actualmente, el Grupo Avianca es propiedad de Synergy Group Corporation, fundado por Germán Efromovich, empresario boliviano, naturalizado brasileño y colombiano. En 2012, Synergy también intentó comprar TAP Portugal, pero su oferta fue rechazada por el Gobierno portugués.

La aerolínea Copa ha optado por una estrategia diferente $\mathrm{y}$ ha utilizado su base en Panamá como centro de conexión de los destinos de larga distancia en América Latina y el resto del mundo. La única excepción que ha hecho fue la compra de Aero República en 2005, desde 2010 denominada Copa Airlines Colombia, siendo la tercera mayor aerolínea en este país.

Las aerolíneas en el Caribe, al igual que las empresas de otros sectores, establecen redes de filiales en varios países para reducir los costes de operación en mercados muy pequeños. La aerolínea nacional de Trinidad y Tobago, Caribbean Airlines, inició operaciones en 2007 para sustituir a West Indies Airways (BWIA), $\square$

1 Resultó una fusión estratégica, y tanto Avianca como Taca mantienen su imagen corporativa. La fusión busca fortalecer los servicios de ambas compañías en la región y lograr generar sinergias. 
firma británica que quebró. En 2010, Caribbean Airlines adquirió las operaciones restantes de Air Jamaica, convirtiéndose también en la aerolínea de bandera jamaicana.

A finales de 2012, Caribbean Airlines se convirtió asimismo en la aerolínea de bandera de Guyana. También destaca Leeward Islands Air Transport (LIAT), otra línea aérea panameña caribeña, que es copropiedad de once Gobiernos del Caribe y cuenta con importantes centros de operaciones en Antigua y Barbuda, Barbados, San Vicente y las Granadinas y Trinidad y Tobago, además de accionistas privados.

Lo que distingue a estos grandes grupos aéreos es, sin duda, su carácter de red. En cada país de la región, la operación del grupo se ejecuta mediante aerolíneas individuales, filiales de una empresa matriz, a fin de cumplir con las exigencias normativas locales de limitar la participación extranjera en la industria aérea. La mayoría de los países latinoamericanos exige que los inversionistas extranjeros solo puedan controlar parcialmente la propiedad de una línea aérea nacional (a menudo no más del 50 por 100) y restringe los vuelos de las líneas aéreas en determinadas rutas, sobre todo en el tráfico interno. Esto añade una carga organizacional a las líneas aéreas que tienen el objetivo de crear este tipo de redes panregionales. En el caso de Avianca y LATAM, esto ha significado trabajar con subsidiarias de propiedad parcial.

Es el caso de LAN, que solo posee el 49 por 100 de LAN Perú y LAN Argentina, y el 45 por 100 de LAN Colombia. Sin embargo, estas empresas son una parte integral de LATAM, que dispone de la propiedad de los aviones en lugar de las compañías aéreas locales. Cuando TAM fue adquirida en 2012 por LAN hubo que suscribir un acuerdo específico para dar cabida a los requisitos legales de Brasil. Al final, TAM es 100 por 100 propiedad de LATAM con sede en Chile, pero el 80 por 100 de los derechos de toma de decisiones políticas recae en inversionistas brasileños, con el propósito de satisfacer la ley de este país, que exige que el 80 por 100 de las compañías aéreas nacionales deben pertenecer a propietarios nacionales. Siguiendo una estrategia similar, Avianca no ha integrado completamente a Lacsa en sus operaciones para mantener el carácter de aerolínea de bandera del que goza en Costa Rica.

La razón por la cual estas grandes redes han tenido éxito en América Latina y el Caribe parece radicar en el menor tamaño relativo de los mercados nacionales y en la fuerte demanda de variadas opciones de vuelos en todo el continente. Además, los empresarios de la región han sido suficientemente creativos para operar dentro de los marcos legales de cada país y explotar las posibilidades de ampliación de sus redes.

Por último, cabe mencionar que no todas las principales aerolíneas de la región participan de este proceso de internacionalización regional, del cual tienden a excluirse aquellas que operan en los principales mercados internos de la región. Así, una de las aerolíneas más grandes de América Latina es Aeroméxico. El operador aéreo mexicano ha seguido una estrategia distinta a la de LATAM o Avianca y se ha centrado en su extensa red nacional, además de en sus conexiones con Estados Unidos. Estas dos características (el mercado interno y las oportunidades en el estadounidense) constituyen probablemente la razón por la cual la compañía aérea no ha sentido la necesidad de operar en red.

Otra gran aerolínea es la brasileña Gol, único operador de bajo costo, que sirve sobre todo al enorme mercado interno. No obstante, $\square$ 
esta es una empresa cotizada, que presenta un gran espacio para la expansión en su mercado nacional.

Todo este amplio accionar indica que las multilatinas se encuentran sometidas a rápidos cambios y variaciones, como lo demuestra la intensa actividad inversora desplegada. Según el Boston Consulting Group (BCG), las multilatinas invirtieron alrededor de 88.000 millones de dólares en M\&A en su expansión regional durante los años 2009-2017, lo que representa más de un cuarto del total de todas las operaciones realizadas en la región durante este periodo, siendo entre otras operaciones significativas las protagonizadas por las multilatinas colombianas y chilenas:

- Grupo Aval (Colombia) compró en Centroamérica el Banco BAC Credomatic, brazo financiero de General Electric, por 1.900 millones de dólares.

- Grupo Aval (Colombia) adquirió la AFP Horizonte de Colombia de BBVA por 530 millones de dólares.

- Grupo Aval (Colombia) se hizo con Editorial El Tiempo, del Grupo Planeta (España), tras adquirirlo por 300 millones de dólares.

- Grupo Aval (Colombia) se hizo con la histórica filial del BBVA en Panamá por 646 millones de dólares.

- Davivienda (Colombia) compró las operaciones del HSBC (Reino Unido) en Costa Rica, Honduras y El Salvador por valor de 801 millones de dólares.

- Grupo Gilinski (Colombia) adquirió las operaciones del HSBC (Reino Unido) en Colombia, Uruguay, Paraguay y Perú por 400 millones de dólares.

- Grupo Sura (Colombia) compró a ING (Holanda), los activos en pensiones, seguros y fondos de inversión en Chile, México, Perú, Uruguay y Colombia. La operación fue de 3.763 millones de dólares.

- Grupo Argos (Colombia) se quedó con diversos activos de la empresa cementera Lafarge (Francia), en Estados Unidos, desembolsando 760 millones de dólares.

- ISA (Colombia) adquirió la filial Intervial Chile de Cintra (España) por 580 millones de dólares.

- Corpbanca (Chile) compró al Grupo Santander (España) la operación Santander Colombia, que se totalizó en 1.225 millones de dólares.

- Corpbanca (Chile) se hizo con HelmBank (EEUU) en Colombia por 1.278 millones de dólares.

- Cencosud (Chile) adquirió los hipermercados Carrefour (Francia) y sus tiendas en Colombia por 2.600 millones de dólares.

- Compañía Sud Americana de Vapores (Chile) se fusionó con Hapag-Lloyd (Alemania), convirtiéndose en la cuarta empresa mundial del sector. La sede central estará en Hamburgo y la central regional, en Santiago de Chile.

Es preciso destacar que estas transacciones indican un cambio importante en el patrón de crecimiento, pues hasta hace algunos años estas M\&A eran casi exclusivamente potestad de empresas multinacionales extranjeras, como puede ser el caso de las españolas. Este auge de las multilatinas demuestra sus excelentes capacidades en la adaptación y transformación de sus recursos para competir exitosamente en la dimensión regional con proyección internacional. 
También es preciso destacar el impacto favorable que causan las multilatinas sobre una cuestión tan importante como es la «integración regional» ${ }^{2}$. Esto se produce debido al voluminoso y creciente nivel de operaciones, proyectos e inversiones que se llevan a cabo en toda la región, haciéndose evidente su contribución en la profundización, cohesión e integración de los mercados latinoamericanos, relacionando productores y consumidores como nunca antes se había logrado y a una velocidad no conocida en los tratados y acuerdos de integración establecidos durante todos estos años ${ }^{3}$. En consecuencia, se hace necesario aprovechar estas dinámicas fuerzas para incorporarlas lo más amplia y extensamente posible, en beneficio de la integración regional, que, por cierto, dista mucho aún de lo planeado.

Como las multilatinas adquieren cada vez más un mayor peso en las respectivas economías nacionales, cabe preguntarse si serán las encargadas de asumir el protagonismo de la modernización de sus respectivos países y por extensión de la región en los mercados internacionales, para, de esta manera, constituirse en la punta de lanza de la productividad ${ }^{4}$ (que representa el tema clave para la competitividad

2 En la XXIII Cumbre Iberoamericana, Ciudad de Panamá, 16-18 de octubre de 2013, en la ceremonia de apertura, el presidente de Panamá, Ricardo Martinelli, expresó solemnemente y con profundidad que «la integración es el futuro nuestro", al tiempo que añadió: "Si reflexionamos sobre el futuro de la Cumbre, concluiremos que los países podrán encontrar en la comunidad iberoamericana una herramienta útil para desarrollarse y fortalecerse en el siglo xx|».

3 Estos acuerdos de integración cubren ampliamente todos y cada uno de los aspectos, y son por sus siglas: ACS, ALADE, ALBA, CA-4, CAN, CARICOM, CELAC, MERCOSUR, NAFTA, OEA, OECS, OTCA, PARLACEM, SELA, SICA, UNASUR y AP.

4 BID, Informe Anual 2014: ¿Cómo repensar el desarrollo productivo? El nuevo marco conceptual que presenta a los países les permite adoptar las políticas de desarrollo productivo necesarias para prosperar, evitando caer en los errores del pasado. El informe replantea el desarrollo productivo a través de la investigación de las fallas de mercado que impiden la transformación y de las fallas de gobierno que pueden convertir los remedios de políticas en algo peor que los males de mercado, utilizando un marco conceptual simple, los autores sistemáticamente analizan las políticas de los países en áreas clave como innovación, financiamiento, capital humano e internacionalización y reconociendo que incluso las mejores políticas fallarán sin la capacidad técnica, organizacional y política para implementarlas. de la región), la innovación y la internacionalización en la nueva geografía económica global del siglo xxI.

Ahora bien, desde otra perspectiva, la pujante dinámica regional e internacional llevada a cabo por las multilatinas, puede verse frenada. No es solo por la variación de las condiciones económicas mundiales, sino por la preocupación sobre los países considerados de «ingreso medio». Puede ser que América Latina se encuentre atrapada en la llamada «trampa del ingreso medio». Dicha trampa se presenta cuando un país de ingreso medio es incapaz de dar el próximo salto para convertirse en una nación de ingreso alto (Foxley, 2012).

América Latina representa un típico caso por contar con el mayor número de países del mundo de ingreso medio, según la clasificación que realiza el Banco Mundial. Las tasas de crecimiento del ingreso per cápita de las economías latinoamericanas durante casi todo el siglo $x x$ fueron inferiores a las de los países desarrollados, lo cual impidió que la región tuviese un proceso de convergencia mayor. Durante los últimos cincuenta años, la región no ha sido tampoco capaz de converger en términos de bienestar con los países desarrollados. Si bien desde 1960 la renta per cápita en dólares constantes se ha multiplicado por 4,5 respecto al ciudadano estadounidense, la brecha de bienestar es hoy un 8 por 100 mayor que la de sus padres o abuelos (BID, 2014).

El estancamiento relativo ha conducido a definir la «trampa del ingreso medio» como aquella situación en la que han caído muchas economías de la región, cuyos costes salariales son demasiado altos para competir en los mercados internacionales frente a otros países que lo hacen basándose en una mano de obra más barata y que, al mismo tiempo, tampoco compiten con aquellos otros países más $\triangleright$ 
avanzados por encontrar dificultades para entrar en la parte más alta de la cadena industrial con productos y servicios intensivos en conocimiento y tecnología (Sanguinetti y Villar, 2012).

Si América Latina se encuentra en esta trampa, serán, en gran parte, las multilatinas (Casilda y Loaiza, 2018) las desactivadoras e impulsoras del salto hacia delante que conduzca a los países hacia mayores crecimientos de la productividad, la industrialización con mayor valor añadido y la internacionalización que les permitirá alcanzar un desarrollo sostenido a largo plazo con la consiguiente mejora del nivel de renta y bienestar social.

\section{Las multilatinas avanzan en el siglo xxI}

El avance de las multilatinas en el siglo XXI quedó debidamente recogido por la Comisión Económica para América Latina y el Caribe (CEPAL), al considerar que ha sido resultado de factores vinculados a las reformas económicas efectuadas por los países, la saturación de los mercados locales, la necesidad de diversificar riesgos y la facilidad de acceso a los mercados de capitales tanto locales como internacionales.

Este avance, desde los primeros años del siglo $\mathrm{xxI}$, se encuentra debidamente analizado por BCG, que desde 2009 elabora la lista de las cien multilatinas más importantes. Para lo cual analiza 5.000 empresas con más de 1.000 millones de dólares en ingresos que hayan crecido más rápido que el promedio regional y que cuentan con operaciones más allá de sus fronteras nacionales. Este destacado grupo de empresas en sectores tan diversos como bienes de consumo, telecomunicaciones e infraestructuras resultan fundamentales para permitir que América Latina logre un crecimiento económico sostenido y, a la vez, impulsen su inserción internacional, su competitividad y su productividad.

México lideró la lista de las 100 mayores multilatinas de 2018. Según BCG, tiene 28; Brasil, 26; Chile, 18; Colombia, 11; Argentina, 9; Perú, 5; y El Salvador, Costa Rica y Panamá una de cada país. Entre las mexicanas más importantes se encuentran: América Móvil, Cemex, FEMSA, Grupo Bimbo, Gruma, Mexichem, Grupo México, Mabe, Metalsa, Televisa, Sigma, Aeroméxico y Grupo BAL. Las brasileñas cuentan con Embraer, Vale, Itaú Unibanco, Globo, Gerdau, Braskem y WEG; las chilenas, con Cencosud, Entel, Falabella y LATAM Airlines; las colombianas, con Avianca, Ecopetrol y Sura; las argentinas, con Arcor, Ternium y Mercado Libre; las peruanas, con Ajegroup y Belcorp; y también están la salvadoreña Grupo Unicomer; la costarricense FIFCO, y la panameña Copa Airlines (Gráfico 1).

La composición de la lista refleja algunas de las profundas transformaciones que han ocurrido en las economías de la región desde el inicio de la publicación de la lista de BCG. Aunque las multilatinas se concentran en México, Brasil, Argentina y Chile, desde los últimos años se observa que las de origen colombiano están ganando peso. Entre los datos clave de 2018, en comparación con los de 2009, se encuentran:

- Mayor diversidad geográfica. Las multilatinas de México, Brasil y Chile siguen liderando la lista en 2018, pero hay más de Argentina, Colombia y Perú, en gran parte debido a la inclusión de instituciones financieras y tecnolatinas. Las de Costa Rica, El Salvador y Panamá también se unieron a la lista. 


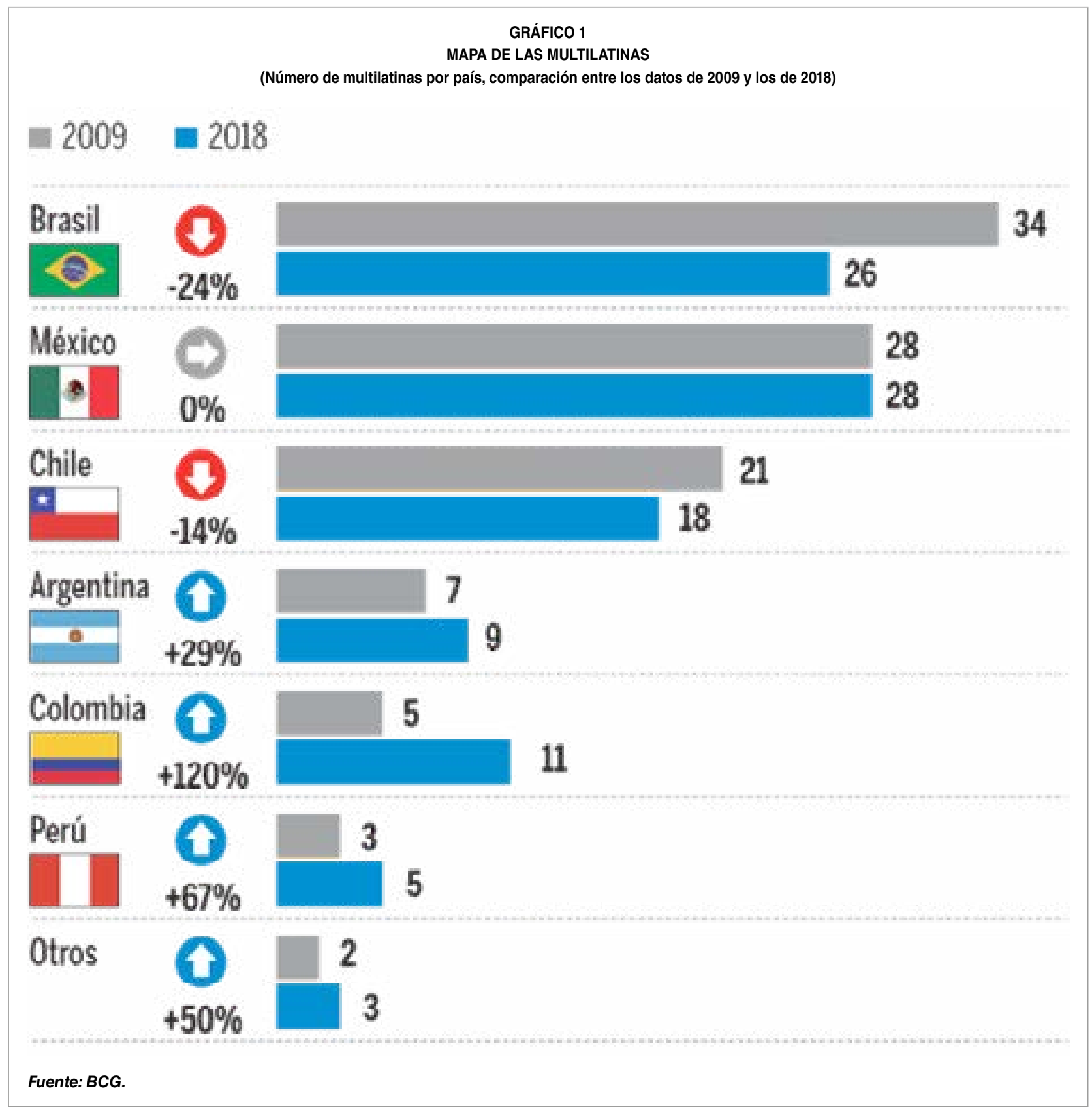

- Una mayor presencia de empresas de consumo. La proporción de multilatinas especializadas en bienes de consumo y servicios que satisfacen las necesidades de la clase media en expansión aumentó del 31 al 44 por 100. El número de empresas de productos básicos cayó de 12 a 7, en gran parte debido a la caída de los precios.

- Creación de valor añadido. El rendimiento medio total para los accionistas aumentó un 12 por 100 anual entre 2000 y 2016, superando con creces el promedio del 8 por 100 de las empresas de mercados emergentes en su conjunto.

- Fuerte contribución a la creación de empleo. El empleo en las multilatinas se expandió un 2,6 por 100 anual entre 2013 y 2016, por encima del promedio regional de solo 0,3 por 100 por año para el mismo periodo. 
Además, durante el periodo 2009-2018, las multilatinas registraron un crecimiento de ingresos anuales de 5,2 por 100 (en dólares estadounidenses), alrededor de tres veces más que el promedio de todas las grandes compañías latinoamericanas. Ahora, con las economías de la región mostrando signos de crecimiento, creemos que las multilatinas están bien posicionadas para ayudar a América Latina al siguiente nivel de internacionalización global.

Entre los desafíos que tendrán que enfrentar las multilatinas, para seguir manteniendo su liderazgo, destacan aspectos fundamentales en el portafolio de negocios, junto con la evolución de la gestión familiar y los modelos de innovación que incorporen, unido a la promoción del talento, representando factores claves para evaluar cómo enfrentan los desafíos de cara a su consolidación regional y expansión internacional. Los cinco factores claves que otorgan ventajas en estos ámbitos son (Becerra, 2018):

- Altos directivos. El entorno empresarial de un país juega un papel importante para la disponibilidad y la retención de los directivos más cualificados, que resultan claves para guiar sólida y eficientemente la expansión global. Según la distribución de los cien CEO más importantes del mundo, Brasil y México son los países de América Latina en donde se concentra la mayoría.

- Mercado de capitales y financiamiento. Para financiar la expansión internacional, las multilatinas regionales necesitan diversificar su acceso tanto al capital como a una financiación relativamente barata, tal como destaca CEPAL (2014).

- Liderazgo de mercado. Las multilatinas internacionalizadas son empresas con fuertes perspectivas de crecimiento, que se refleja en el mayor crecimiento de las ventas, respecto a las multilatinas regionales y empresas locales.

- Adquisiciones y alianzas estratégicas. La estrategia de expansión internacional es probable que se base en el crecimiento inorgánico a través de adquisiciones y creación de empresas conjuntas. En promedio, estas compañías ejecutan casi cuatro veces más joint ventures $\mathrm{y}$ más de seis veces el número $M \& A$.

- Prácticas de gobierno. La adopción de las prácticas líderes de gobierno corporativo internacional ayuda a las multilatinas a operar con mayor eficacia globalmente. Además, les ayuda a obtener acceso al capital de los fondos de pensiones estatales y a los fondos soberanos, que tienen reglas estrictas sobre el tipo de empresas en las que invierten.

Estos cinco factores son considerados claves para el ascenso en la curva de madurez y la expansión internacional, siendo tres de estos factores competencias en las que las empresas pueden influir a través de sus propias acciones:

- Adoptando una posición de liderazgo en el mercado del propio país.

- Adoptando estrategias que se centran en adquisiciones y joint ventures como el medio principal para el crecimiento internacional y global.

- Adoptando prácticas líderes de gobierno corporativo de alcance internacional y global.

Las multilatinas internacionales y globales tienden a ser muy fuertes en estas tres áreas, de manera que cualquier empresa, local o $D$ 
regional, que aspira a alcanzar un nivel internacional y global es muy probable que tenga que adoptarlos. Los otros dos factores son de carácter más estructural, indicando que están determinados en gran medida por el entorno local:

- La disponibilidad y la retención de los directivos más cualificados para liderar la expansión internacional y global.

- El acceso a los mercados de capitales y el financiamiento internacional.

Como las empresas no tienen un control directo total sobre los cinco factores, necesariamente deben disponer de las correspondientes estrategias alternativas. Poder contar con los cinco factores, debidamente organizados y alineados, ofrece una clara ventaja competitiva. Sin embargo, esto no garantiza totalmente el éxito, pues no existe una sola fórmula para la expansión internacional y global. Diferentes empresas se enfrentarán a diferentes oportunidades y obstáculos, y seguirán diferentes caminos. Sin embargo, las multilatinas regionales pueden, mediante la aplicación de estos cinco factores, obtener mayores posibilidades de éxito en su expansión internacional y global.

Según INTAL, la presencia de las multilatinas se extiende a 114 países donde al menos una está instalada. Si bien estos avances han sido importantes, son pocas las multilatinas que pueden considerarse como jugadores verdaderamente globales, tanto por limitaciones de tamaño como por la todavía insuficiente acumulación de capacidades para competir en las fronteras de sus actividades. A ello se suma que, salvo en Brasil, no hay políticas explícitas de apoyo a estas empresas en la región.

Por otro lado, son escasos los ejemplos de multilatinas que operan en actividades intensivas en conocimientos y valor añadido, reflejando el patrón de especialización productiva predominante en la región basado en los recursos naturales. Aunque no siempre su internacionalización genera derrames y encadenamientos sobre sus economías de origen, por ejemplo, sobre el desarrollo de proveedores. Ello requiere una agenda a futuro tanto para consolidar la presencia global de estas empresas como para mejorar sus impactos sobre sus respectivos países (INTAL).

Definitivamente, las multilatinas, dentro y fuera de América Latina, ganan atención en la literatura especializada, al igual que to hacen en los foros, como sucedió en la XXI y XXIII Cumbre Iberoamericana, donde en su discurso inaugural, el secretario general iberoamericano, Enrique V. Iglesias, se refirió a las multilatinas y su fuerza para competir internacionalmente y a cómo cabría reflexionar y en qué forma los países de la Comunidad Iberoamericana pueden reforzarse mutuamente, potenciando sus relaciones para enfrentar la dura competencia internacional enmarcada en un contexto global (Gráfico 2).

Respecto al papel de las multilatinas en la proyección internacional de sus países, el ejemplo más próximo lo tenemos en las multinacionales españolas. El proceso de incorporación de España como actor de primera línea se encuentra ampliamente relacionado con la génesis de sus multinacionales. Y es que el poder como la influencia de los países en un mundo interrelacionado y global, exceptuando el poder militar, se encuentra directamente asociado al poder e influencia que despliegan y ejercen sus empresas multinacionales.

En cuanto al valor bursátil de las multilatinas, Standard \& Poor's Latin America $40^{5} \square$

5 El S\&P Latin America 40 es un índice bursátil de Standard \& Poor's, que realiza un seguimiento de las acciones de América Latina. Es uno de los siete índices principales que componen S\&P Global 1200 que 
GRÁFICO 2

LAS MULTILATINAS. THE BOSTON CONSULTING GROUP 2018

EXHIBIT 1 | The 2018 BCG Multilatinas

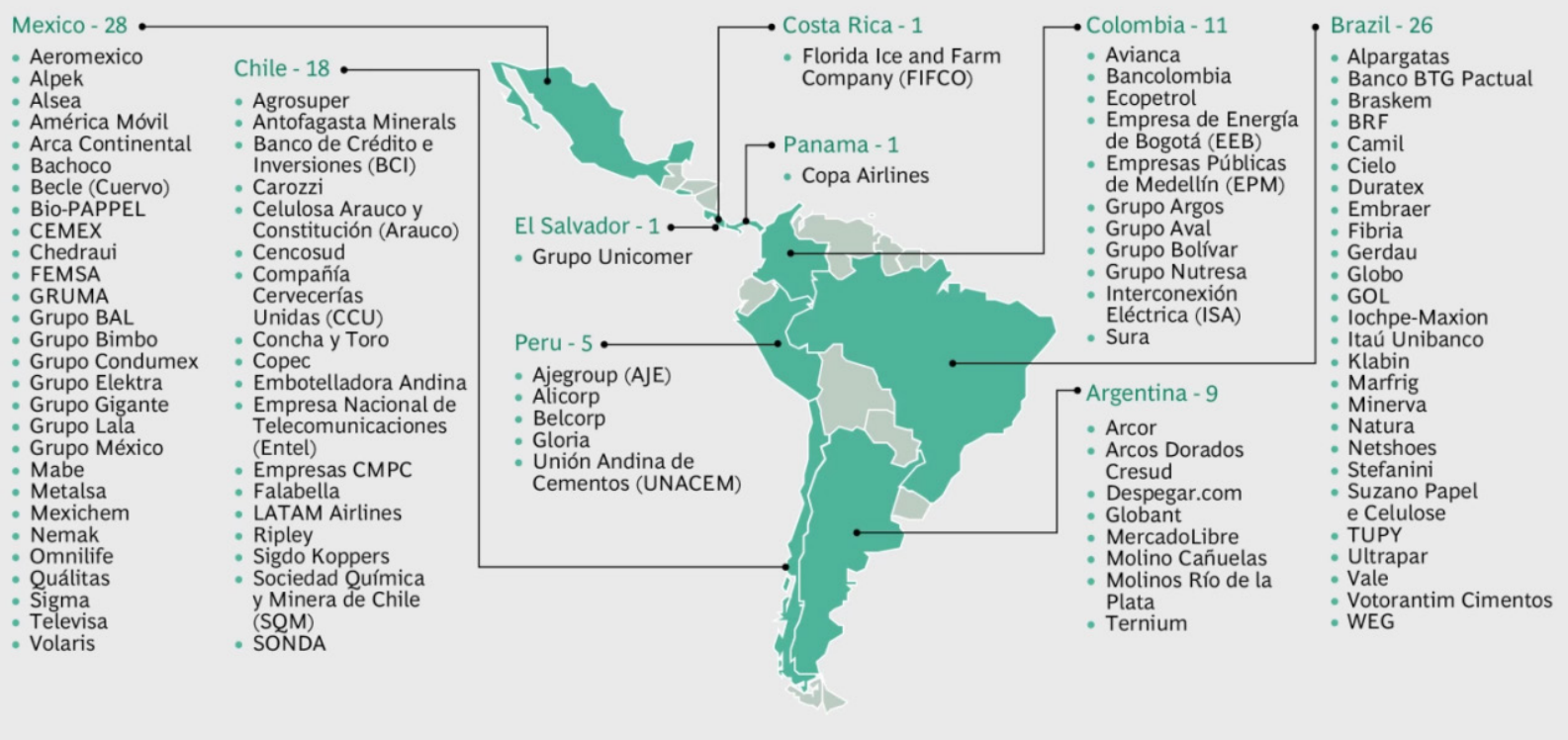

Fuente: BCG analysis.

indica que las brasileñas cuentan con un importante liderazgo en la región. La primera multilatina global más valiosa es la brasileña Compañía de Bebidas de las Américas (AmBev), una firma que nació de la fusión entre Antarctica y Brahma, y que unos años después selló una alianza con Interbrew, convirtiéndose en una de las mayores cerveceras del mundo por volumen de ventas. Le sigue el conglomerado financiero Itaú Holding, que aumentó sustancialmente su valor después de asociarse con Unibanco. La lista la completan la petrolera Petrobras, de propiedad mayoritariamente estatal; la Companhia Vale do Rio Doce (Vale), que opera en los sectores de minería, logística, energía siderúrgica y petróleo; y Bradesco, uno de los mayores

incluye valores altamente líquidos de los principales sectores económicos de los mercados de valores. Empresas de Brasil, Chile, Colombia, México y Perú están presentes en este índice, representando aproximadamente el 70 por 100 de la capitalización bursátil de cada país. bancos privados de Brasil y de América Latina (Cuadro 1).

América Latina, desde una perspectiva amplia, debe posicionarse en la economía global con multilatinas de mayor tamaño y valor bursátil, avanzadas y competitivas: De no conseguirlo, muy posiblemente la región no tendrá el lugar que realmente le corresponde en la escena internacional y, además, no será protagonista del mundo del siglo xxI.

\section{CUADRO 1}

LAS MULTILATINAS MÁS VALIOSAS POR CAPITALIZACIÓN BURSÁTIL

\begin{tabular}{|l|c|l|}
\hline \multicolumn{1}{|c|}{ Multilatina } & $\begin{array}{c}\text { Valor en miles } \\
\text { de millones } \\
\text { de dólares }\end{array}$ & País \\
\hline AmBev & 101.000 & Brasil \\
Itaú Unibanco & 81.000 & Brasil \\
Petrobras & 63.000 & Brasil \\
VALE & 61.000 & Brasil \\
Banco Bradesco & 61.000 & Brasil \\
\hline
\end{tabular}

Fuente: S\&P Latin América 40 


\section{Las multilatinas y España como puente internacional o hub para Europa}

Si estamos de acuerdo en que las multilatinas deben ampliar sus perspectivas internacionales en un contexto global, entonces necesariamente deben aprovechar las ventajas que ofrecen los distintos países, como puede ser la «facilidad» que les ofrece España como «puente» internacional para Europa. Para lo cual cuentan, al igual que las empresas españolas en América Latina, con vínculos históricos-culturales, un idioma común y una red muy importante de relaciones económicas, comerciales y financieras, tejidas en gran parte por las propias empresas españolas presentes en los países latinoamericanos.

Este camino de «ida y vuelta», que desde siempre aliento, es decir, transitar en las dos direcciones, tiene mucho sentido. Las empresas españolas, es evidente, ya lo han hecho y continúan haciéndolo. Ahora les corresponde a las multilatinas acometer vigorosamente una expansión que ya comienza a percibirse con el desembarco de relevantes grupos e inversores latinoamericanos. Este viaje hacia España lo protagonizan, en primer lugar, las grandes multilatinas mexicanas (Casilda, 2014), seguidas de las brasileñas y colombianas. Se sentirán muy arropados.

España cuenta con la presencia de relevantes organismos iberoamericanos: Secretaría General Iberoamericana (SEGIB), Unión de Ciudades Capitales Iberoamericanas (UCCI), Mercado de Valores Latinoamericano en euros (Latibex), Organización de Estados Iberoamericanos (OEI), Asociación Universitaria Iberoamericana de Postgrado, Organización Iberoamericana de Seguridad Social, Secretaría Cumbres Unión Europea-América Latina-
Caribe (UE-LAC), Corporación Financiera lberoamericana $(\mathrm{CFI})$, Federación Iberoamericana de Fondos de Inversión (FIAFIN), Federación Internacional de Administradores de Fondos de Pensiones (FIAP), Federación Interamericana Empresas de Seguros (FIDES), Organización Internacional de Comisiones de Valores (IOSCO), Comité Interamericano de IOSCO, y las oficinas de representación europea de los dos principales bancos multilaterales de desarrollo, como son el Banco Interamericano de Desarrollo (BID) y la Corporación Andina de Fomento-Banco de Desarrollo de América Latina (CAF).

España apuesta con decisión como plataforma o hub de negocios e inversiones internacionales, pues realmente cuenta con posiciones diferenciadoras positivas y competitivas para la inversión, facilitando el acceso a los mercados de Unión Europea y norte de África. En este sentido, es preciso resaltar la organización y puesta en marcha del Plan de Atracción de Sedes e Inversiones de Empresas Multilatinas en España (ICEX-Invest in Spain, 2017), cuyo objetivo no es otro que impulsar y reforzar como principal plataforma o hub de negocios internacionales de estas empresas hacia Europa y norte de África.

Un dato importante lo representan los 1.543 proyectos greenfield latinoamericanos, lo que convierte a España en el primer destino europeo para estos proyectos. Además, las relaciones empresariales con América Latina se ven favorecidas por la extensa red, tanto de Convenios de Doble Imposición (CDI) como de los Acuerdos para la Promoción y Protección de Inversiones (APPRI), que ha contribuido de forma especial a que muchas empresas latinoamericanas se hayan establecido ya en España. Por lo cual, España puede y debe ser el destino natural de las multilatinas en proceso expansivo, y también de aquellas que $D$ 
CUADRO 2

LATIBEX. EMPRESAS COTIZADAS. CAPITALIZACIÓN Y EVOLUCIÓN BURSÁTIL EN 2017

\begin{tabular}{|c|c|c|c|c|}
\hline Empresas & País & Industria & $\begin{array}{c}\text { Capitalización } \\
\text { (millones de euros) }\end{array}$ & Evolución 2017 (\%) \\
\hline Alfa $\mathrm{C} / \mathrm{I}-\mathrm{S} / \mathrm{A}$ & México & Conglomerado & 4.634 & $-31,90$ \\
\hline América Móvil & México & Telecomunicaciones & 31.977 & 21,72 \\
\hline Bradesco & Brasil & Banca & 25.740 & 2,77 \\
\hline Santander Rio & Argentina & Banca & 2.112 & $-21,08$ \\
\hline Banorte & México & Banca & 14.429 & 13,14 \\
\hline BBVA Banco Francés & Argentina & Banca & 3.682 & 22,95 \\
\hline Bradespar & Brasil & Gestión de activos & 2.362 & 66,45 \\
\hline Bradespar Pref & Brasil & Gestión de activos & 2.362 & 61,85 \\
\hline Braskem Pr.A & Brasil & Química & 3.748 & 2,00 \\
\hline Cemig P. & Brasil & Utilities & 1.467 & $-22,52$ \\
\hline Copel Pr.B & Brasil & Utilities & 809 & $-22,20$ \\
\hline Eletrobrás Pre & Brasil & Utilities & 6.493 & $-29,28$ \\
\hline Eletrobrás & Brasil & Utilities & 6.493 & $-30,49$ \\
\hline Geo Ord.B & México & Construcción residencial & 32 & $-80,68$ \\
\hline Gerdau Pref & Brasil & Acero & 3.545 & $-2,12$ \\
\hline Grupo Elektra & México & Grandes almacenes & 7.302 & 146,33 \\
\hline Petrobras & Brasil & Petróleo y gas & 52.727 & $-12,86$ \\
\hline Petrobras Preferentes & Brasil & Petróleo y gas & 52.727 & $-7,19$ \\
\hline Sare B & México & Construcción residencial & 55 & 0,00 \\
\hline Tv Azteca & México & Broadcasting - TV & 306 & $-2,63$ \\
\hline Usiminas & Brasil & Acero & 3.082 & 4,24 \\
\hline Usiminas Preferentes & Brasil & Acero & 3.082 & 90,04 \\
\hline Vale & Brasil & Minerales y metales & 68.149 & 23,88 \\
\hline Vale Preferentes & Brasil & Minerales y metales & 68.149 & 29,08 \\
\hline Volcan B & Perú & Minerales y metales & 757 & 63,16 \\
\hline
\end{tabular}

comiencen su expansión internacional en Europa, norte de África e incluso Oriente Medio y, por qué no, Asia, pensando en China, cuyos lazos se ven reforzados mediante el establecimiento de operaciones triangulares.

Otro dato complementario e importante a tener muy en cuenta es que las multilatinas, en muchos casos, cotizan en España a través del Mercado de Valores Latinoamericano en euros $(\text { Latibex })^{6}$. Latibex es un mercado bursátil para empresas latinoamericanas radicado en Madrid,

6 Latibex representa la avanzada de un movimiento más amplio, que proseguirá con otras multilatinas de diferentes sectores, como las ligadas al consumo, la alimentación, la restauración o la moda. que opera desde diciembre de 1999. Está regulado por la Ley del Mercado de Valores española y forma parte del holding Bolsas y Mercados Españoles (BME). Utiliza la misma plataforma de negociación de valores que la bolsa española, y los valores que lo integran cotizan en euros. Fue creado para, por un lado, permitir a los inversores europeos comprar y vender valores iberoamericanos a través de un único mercado, con unos estándares de seguridad y transparencia homogéneos y en una sola divisa, el euro; y, por el otro, dar acceso a las principales empresas iberoamericanas al mercado europeo de capitales. 
CUADRO 3

LATIBEX. EMPRESAS COTIZADAS, FACTURACIÓN Y BENEFICIOS EN 2017

(Millones de dólares)

\begin{tabular}{|l|c|c|c|c|c|c|c|}
\hline \multicolumn{1}{|c|}{ Empresas } & $\begin{array}{c}\text { Facturación } \\
\mathbf{2 0 1 7}\end{array}$ & $\begin{array}{c}\text { Facturación } \\
\mathbf{2 0 1 6}\end{array}$ & $\begin{array}{c}\text { \% } \\
\text { Variación }\end{array}$ & $\begin{array}{c}\text { Beneficios } \\
\mathbf{2 0 1 7}\end{array}$ & $\begin{array}{c}\text { Beneficios } \\
\mathbf{2 0 1 6}\end{array}$ & $\begin{array}{c}\text { \% } \\
\text { Variación }\end{array}$ & Empleados \\
\hline América Móvil & 51.919 & 33.967 & 52,9 & 1.490 & 440 & 239 & 194.193 \\
Bradesco & 18.340 & 18.859 & $-2,8$ & 5.745 & 5.170 & 11 & 98.808 \\
Gerdau & 11.148 & 11.370 & $-1,9$ & -102 & -871 & -88 & 36.857 \\
Petrobrás & 85.667 & 85.333 & 0,4 & 114 & -3.939 & -103 & 68.829 \\
Vale & 33.967 & 27.488 & 23,6 & 5.507 & 3.982 & 38 & 73.062 \\
\hline Fuente: Latibex. & \multicolumn{7}{|r|}{} \\
\hline
\end{tabular}

Las empresas cotizadas en Latibex (Cuadro 2), durante el ejercicio 2017, obtuvieron importantes ganancias respecto a 2016 (Cuadro 3). Destacan tres grandes multilatinas que conjuntamente registraron un importante nivel de beneficios situados en 12.754 millones de dólares. Estas son: la minera brasileña Vale, el banco brasileño Bradesco y la operadora mexicana América Móvil. El lado negativo se encuentra en la petrolera brasileña Petrobras, que perdió 140 millones de dólares, y el grupo siderúrgico brasileño Gerdau, al encadenar tres años consecutivos de pérdidas. Los resultados de estas cotizadas han sido los siguientes:

- Vale es una empresa minera brasileña fundada en 1942 con sede en la ciudad de Río de Janeiro. Además opera en los sectores de energía siderúrgica y petróleo, siendo uno de los mayores operadores logísticos de Brasil. Es también la segunda compañía minera más grande del mundo y el mayor productor mundial de hierro, siendo el segundo en níquel. En el sector de la energía eléctrica participa en consorcios y actualmente opera en nueve plantas hidroeléctricas. Obtuvo un beneficio neto de 5.424 millones de dólares en 2017, lo que representa un aumento de 32,4 por 100 con respecto al año 2016, que registró un beneficio neto de 4.095 millones de dólares, frente a las pérdidas de 13.604 millones de dólares en 2015. Los resultados favorables se debieron a los mayores precios de los minerales y al menor deterioro en activos de operaciones discontinuas, que fueron parcialmente compensados por el impacto negativo en la variación cambiaria del real brasileño frente al dólar.

- Bradesco es el segundo mayor banco privado de Brasil y de América Latina (en activos totales), creció principalmente a través de fusiones y adquisiciones. Fue fundado en 1943 en la ciudad de Marília (São Paulo). Su nombre original era Casa Bancaria Almeida y, seguidamente, Banco Brasileño de Descuentos SA, cuya sigla era Bradesco, que pasó a ser la razón social y registró un beneficio neto de 5.984 millones de dólares en 2017, lo que representa un incremento de 11,1 por 100. Los resultados fueron positivos por «la reducción del gasto de provisión para deudores dudosos, el incremento de los ingresos en la prestación de servicios", así como en la parte de «seguros, planes de pensiones y capitalización» y también por la disminución del margen financiero, entre otros factores.

- América Móvil es la empresa líder en servicios integrados de telecomunicaciones $\triangleright$ 
en Latinoamérica. El despliegue de su plataforma de comunicaciones le permite ofrecer a sus clientes un portafolio de servicios de valor agregado y soluciones de comunicación en 25 países de América y Europa. Obtuvo un beneficio de $1.564 \mathrm{mi}-$ llones de dólares, tres veces más que en 2016. Los ingresos crecieron hasta los 53.300 millones de dólares, con un aumento del 4,7 por 100 respecto al año anterior. La mayor expansión del negocio se logró en Perú, con un incremento del beneficio de 138,7 por 100 , seguido de Brasil $(81,1$ por 100) y del grupo formado por Argentina, Paraguay y Uruguay (29,8 por 100$)$. En cambio, el resultado de Ecuador cayó un 21,4 por 100, el de México se redujo un 5,6 por 100 y el de Chile, aunque mejoró un 35,5 por 100 , registró pérdidas.

- Petróleo Brasileiro SA (Petrobras) es una empresa brasileña de naturaleza semipública de propiedad mayoritariamente estatal y con participación extranjera privada. Petrobras opera de forma activa en el mercado internacional de petróleo como también a través del intercambio de una importante diversidad de productos relacionados con la industria petroquímica. Entre otras cosas, destaca por utilizar alta tecnología en operaciones de exploración y producción de petróleo en aguas abiertas (offshore), contando con el récord de la planta de producción de crudo más profunda del mundo. Ocupa el cuarto lugar en el ranking de las mayores empresas petrolíferas internacionales de capital abierto en el mundo. Desde mediados del año 2009, se sitúa como la mayor compañía de América Latina, superando en sus ventas, desde 2009, a gigantes que durante años habían estado delante, como la mexicana PEMEX y la venezolana PDVSA. Para Petrobras, 2017 resultó un buen ejercicio: revalorizó activos, redujo burocracia y vendió un 32 por 100 más para lograr un resultado operativo de 11.132 millones de dólares, el doble que en 2016. Pero para evitar un juicio en Estados Unidos por el escándalo de corrupción Lava Jato, del que la compañía es protagonista y "víctima», tal como defienden en la empresa, debe indemnizar a los inversores con 2.950 millones de dólares. Por lo tanto, el buen ejercicio de 2017 finalizó con pérdidas, concretamente de 140 millones de dólares. De no ser por el escándalo, habría ganado 2.215 millones de dólares. Aun así, son las menores pérdidas de los últimos cuatro años.

- Gerdau es el grupo siderúrgico brasileño que cuenta con operaciones industriales en catorce países (en EEUU es donde más plantas tiene, también Europa y Asia), las que suman una capacidad instalada superior a 25 millones de toneladas al año. Es la mayor recicladora de Latinoamérica y, en el mundo, transforma anualmente millones de toneladas de chatarra en acero, reforzando su compromiso con el desarrollo sostenible de las regiones donde actúa. Las pérdidas de 2017 fueron de 105,9 millones de dólares. A pesar del resultado negativo, la mejoría es evidente, puesto que en 2016 registró pérdidas por 901,5 millones de dólares. Durante 2017, el grupo redujo la deuda neta un 19,8 por 100 , debido al agresivo plan de ventas de activos en Brasil y en otros países con el objetivo de mejorar el perfil financiero. $D$ 


\section{Conclusiones}

Ante el favorable clima económico que impulsaba la dinámica de expansión regional e internacional, actualmente las multilatinas se encuentran ante un contexto y un entorno económico menos favorable. Ya no cuentan con los vientos favorables de los altos precios y la creciente demanda de materias primas, ni con el potente crecimiento de China ni con los bajos tipos de interés en Estados Unidos y un dólar depreciado. Estos impulsos han cesado, en la medida que los propios Gobiernos, los expertos y los organismos internacionales han revisado a la baja sus previsiones de crecimiento debido a que Latinoamérica sufre una suave pero persistente desaceleración generalizada y, en algunos países, un estancamiento y, en otros, un decrecimiento. Así que las multilatinas se enfrentan al dilema de replegarse y concentrarse en sus mercados de origen y resistir o, por el contrario, acrecentar su presencia regional e internacional.

Sin dudas, el contexto y el entorno económicos han variado, lo cual merma sus capacidades de maniobra y sus estrategias de crecimiento regional e internacional, y los Gobiernos no pueden ayudarles. Aunque bien es cierto que son los Gobiernos los que deben crear el ambiente y el clima adecuados, no conviene olvidar que son las empresas a las que les corresponde asumir el protagonismo en su proceso de internacionalización. Serán ellas las que, desde sus políticas y estrategias, determinen si su apuesta regional e internacional continúa - como es el caso de sus inversiones en España-, o por el contrario se repliegan y aguardan a que los vientos vuelvan a ser más intensos y favorables.

\section{Bibliografía}

[1] BECERRA. J. (2018). «Los desafíos de las Multilatinas». Economía y Negocios (en línea). Disponible en: http://www.economiaynegocios.cll

[2] CASILDA BÉJAR, R. (2003). «Brasil». Revista Información Comercial Española, n. ${ }^{\circ} 810$. Madrid.

[3] CASILDA BÉJAR, R. (2011). «La importancia del efecto sede en la globalización». El País. Madrid (10 de abril).

[4] CASILDA BÉJAR, R. (2012). América Latina Emergente. Economía, desarrollo, industrialización, multilatinas, geoeconomía. Madrid: Editorial Universitaria Ramón Areces.

[5] CASILDA BÉJAR, R. (2013). «La Alianza del Pacífico y la Cumbre de Cali». El País Digital (en línea). Disponible en: www.economia.elpais.com (10 de junio).

[6] CASILDA BÉJAR , R. (2014). «España-Brasil: dos socios con intereses crecientes». Boletín Económico de Información Comercial Española, n. ${ }^{\circ}$ 3054. Madrid.

[7] CASILDA BÉJAR, R. (2014). «Las multilatinas. Una mención especial a las mexicanas». Boletín de Información Comercial Española, n. ${ }^{\circ}$ 3052. Madrid.

[8] CASILDA BÉJAR, R. (2018). Crisis y reinvención del capitalismo. Madrid: Delta Publicaciones. Grupo Ediberun, Madrid, Buenos Aires, México, Lima y Bogotá.

[9] CASILDA, R.; BULNES, A. y LOAIZA, C. (2018). Inversiones españolas en Latinoamérica. La internacionalización de las empresas españolas y el resurgimiento de las multilatinas en el siglo XXI. Montevideo: Ediciones La Ley-Thomson Reuters.

[10] CEPAL (2015). La Inversión Extranjera Directa en América Latina y el Caribe. Santiago de Chile. Disponible en: http://repositorio.cepal. org/bitstream/handle/11362/38214/ S1500535_es.pdf

[11] DE GROOT, O. y PÉREZ LUDEÑA, M. (2014). Foreigndirect investment in the Caribbean: trends, determinants and policies. CEPAL (Caribbean Studies and Perspectives, n. 35 , LC/L.3777).

[12] ICEX-INVEST IN SPAIN (2017). España, plataforma para las inversiones y sedes de $D$ 
empresas multilatinas en Europa, África y Oriente Medio. Disponible en: http://www.investinspain.org/

[13] INTAL (2018).Exportando multilatinas.Disponible en: $h$ ttps://intal-interactivo.iadb.org/? $p=38$
[14] SANGUINETTI, P. y VILLAR, L. (2012). «Patrones de desarrollo en América Latina. ¿Convergencia o caída en la trampa del ingreso medio?" CAF. Documentos de trabajo, n. ${ }^{\circ}$ 2012/02. Julio. Caracas. 